\title{
Dynamic Voltage Restorer with Active Disturbance Rejection Control
}

\author{
Looja Ratna Tuladhar and F. Eugenio Villaseca \\ Department of Electrical and Computer Engineering, Cleveland State University, Cleveland OH 44115, USA
}

Received: September 14, 2014 / Accepted: October 13, 2014 / Published: December 31, 2014.

\begin{abstract}
Power quality is one of the major concerns among consumers and electric utility companies. CUPS (custom power systems) devices are used to improve the quality of power and enhance the reliability of the power supply in the distribution networks. The DVR (dynamic voltage restorer) is an important CUPS device used to mitigate voltage sag/swell and imbalances. Various control techniques have been implemented to control the DVR, among which the PID (proportional-integral-derivative) controller is dominant because of its model independent property and its error driven technique. In this paper, a new controller based on the ADRC (active disturbance rejection control) concept is developed, and its performance is compared to that of the PID controller. The model of the DVR and its ADRC and PID controllers were developed under the MATLAB (matrix laboratory)/Simulink ${ }^{\mathcal{O}}$ environment. The simulation results demonstrated the effectiveness of the ADRC over the PID controller.
\end{abstract}

Key words: ADRC, CUPS, control systems, DVR, PID control, power quality, voltage sag/swell.

\section{Introduction}

Power quality is one of the major concerns in the field of electric power systems which has a direct impact on economics. Today, maintaining or improving power quality and customer satisfaction has become a major challenge. There are many problems associated with power quality, such as voltage sags, voltage swells, voltage imbalances, transients, interruptions, harmonics, voltage flicker, power frequency variation and poor power factor. Voltage sags are one of the most common power quality problems faced by industrial customer. IEEE Standard 1159-1995, IEEE Recommended Practice for Monitoring Electric Power Quality, defines the voltage sag as a decrease in effective (rms) voltage between 0.1 pu (per unit) and $0.9 \mathrm{pu}$, for durations from 0.5 cycles to $1 \mathrm{~min}$ [1]. An example of voltage sag is shown in Fig. 1.

The various causes for voltage sags include system faults and switching of large loads. A fault on a feeder

Corresponding author: Looja Ratna Tuladhar, doctoral candidate, research fields: power systems, power electronics and controls. E-mail: 1.tuladhar@vikes.csuohio.edu. will cause a voltage drop on other parallel feeders until the fault is cleared. When starting a large load, such as a large electric motor, the large inrush current in the machine can cause voltage sags in the local or adjacent areas, even when the utility line voltage is constant at nominal voltage. The key problem caused by voltage sags in the manufacturing industry is unplanned downtime, resulting in reduced productivity and monetary losses. Problems are limited not only to productivity, but also to product quality and even damage to sensitive equipment. Some areas where power quality really matters are hospitals, air traffic control centers, database systems, etc., even when equipped with non-interruptible power supplies.

\subsection{Custom Power Systems}

The concept of CUPS (custom power systems) was introduced in 1995 to improve the power quality and enhance the reliability of the power supply in the distribution networks [2]. Like FACTS (flexible AC transmission systems) devices, CUPS devices are high power electronics units. CUPS devices include 


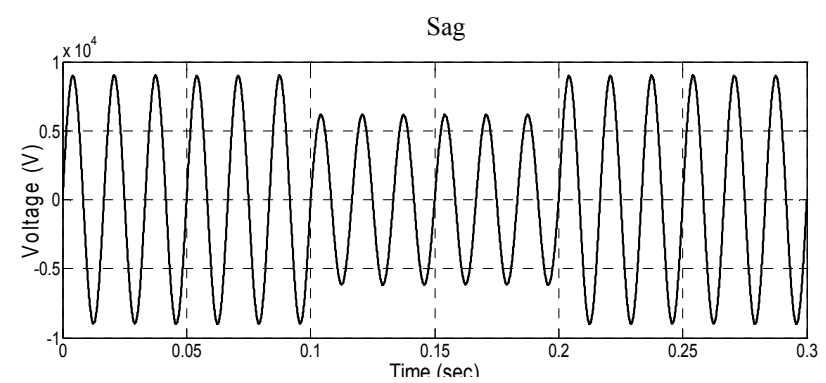

Fig. 1 Voltage sag.

DVR (dynamic voltage restorer), D-STATCOM (distribution static compensator), D-SSSC (distribution static synchronous series compensator), and UPQC (unified power quality conditioner).

\subsection{Dynamic Voltage Restorer}

A schematic of a DVR is shown in Fig. 2. It is a VSC (voltage source converter)-based device connected in series with the distribution line through a boosting transformer. A DVR protects sensitive loads from voltage sags/swells in the supply voltage. It can also inject a set of unbalanced voltages of the appropriate magnitude and phase, to maintain balanced and rated voltages at the load terminal during unbalanced sags or swells.

DVRs monitor the load voltage waveform continuously, and when they detect any of the aforementioned disturbances, they inject the proper voltage in the distribution feeder through a series transformer in order to maintain the reference voltage level. The amplitude and phase angle of the injected voltages can be controlled to facilitate exchange of the real and reactive power between DVR and the distribution system. The reactive power exchange is done within the DVR itself without the need of an external energy storage device, but it does require an external energy storage device to exchange real power at the DVR output.

\section{DVR Controller}

The first PID (proportional-integral-derivative) controller was used in 1922 for steering a ship [3]. Since then, it has become very popular and it is still the

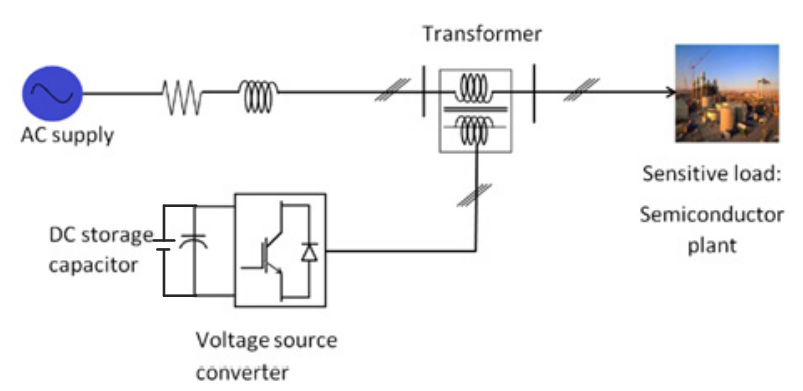

Fig. 2 The DVR.

dominating control technology in industry. Besides PID, many other modern control techniques have been developed but have yet to be widely adopted. Modern controllers do indeed contribute to the improvement of performance, but are complex in their design and implementation. Also, we can not ignore the fact that the PID controller is the most used controller for CUPS devices. Unlike model-based modern controllers, the PID controller is an error-driven model-independent controller.

The model-based controller is a perfect controller provided the model of the plant is also exactly known. If there was a way to obtain an exact model for a plant, then, the model-based controller would be the ideal controller. Unfortunately, only approximate plant models can be obtained using some known system identification techniques, and it is a real challenge when the plant dynamics are nonlinear, subject to disturbances and measurements are corrupted by noise. The result is typically an approximation to a reduced-order model. The development of a method to obtain a low-cost process model was highlighted in Ref. [4] as one of the challenging research opportunities in the control field.

The replacement of the highly dominating PID controller by an ADRC (active disturbance rejection controller) was proposed in Ref. [5]. ADRC is considered as a partially model-based controller, since it requires very little information from the plant. It is a combination of a PID controller and a partially modeled-based modern control theory. It takes the error driven control law from the PID control concept and a state observer from modern control theory. The 
ADRC algorithm actively estimates and compensates for the effects of unknown dynamics and disturbances in the plant. These are estimated by the use of an ESO (extended state observer). Then, this estimated value is provided to the controller to compensate for the disturbances. A variety of techniques have been developed to control the DVR to achieve its functions. In Refs. [6-9], PID control has been successfully applied to control the DVR. Also, the application of controllers, such as SMC (sliding mode control) and hysteresis control to APF (active power filter) are demonstrated in Refs. [10, 11], respectively. In Ref. [12], hysteresis control method is used to control the series APF of unified voltage conditioner.

\section{ADRC Design}

Considering that we do not have a precise mathematical system model, and the system is represented by the following second order system, as explained in Ref. [13]:

$$
\ddot{y}=b u+f(y, \dot{y}, w, t)
$$

where, $y, u, w, b, t, \dot{y}$ and $\ddot{y}$ are output signal, input signal, external disturbance, system parameter, time, first time derivative of output signal, and second time derivative of output signal, respectively, and $f(y, \dot{y}, w, t)$, or simply denoted as $f$ is a nonlinear system function including disturbances and uncertainties, also known as total disturbance.

Once the estimate of $f, \hat{f}$ is obtained, the new control signal $\left(u_{0}\right)$ will be as follows:

Then:

$$
\begin{gathered}
u_{0}=b u+\hat{f} \\
\ddot{y}=u_{0}-\hat{f}+f
\end{gathered}
$$

$$
\ddot{y} \approx u_{0}
$$

which is a pure double-integral system without the external disturbance and internal uncertainties, and $u_{0}$ can be easily designed to meet performance specifications. The challenge is to obtain the estimate $\hat{f}$. The procedure is to include it as an additional state variable. The extended state observer is used to estimate $f, y$, and $\dot{y}$.

Representing Eq. (1) in state space form:

$$
\left.\begin{array}{c}
\dot{x}_{1}=x_{2} \\
\dot{x}_{2}=x_{3}+b u \\
\dot{x}_{3}=\dot{f}=h \\
y=x_{1}
\end{array}\right]
$$

where, $x_{1}, x_{2}$ and $x_{3}$ are the state vectors and $\dot{x}_{1}, \dot{x}_{2}$ and $\dot{x}_{3}$ are time derivatives of $x_{1}, x_{2}$ and $x_{3}$, respectively. $x_{3}=f$ is an additional or extended state, which is estimated to obtain the desired $\hat{f}$.

Then, the state space model is given by:

$$
\left.\begin{array}{c}
\dot{x}=\mathrm{A} x+\mathrm{Bu}+\mathrm{E} h \\
y=\mathrm{C} x
\end{array}\right]
$$

where,

$$
\mathrm{A}=\left[\begin{array}{lll}
0 & 1 & 0 \\
0 & 0 & 1 \\
0 & 0 & 0
\end{array}\right] ; \mathrm{B}=\left[\begin{array}{l}
0 \\
b \\
0
\end{array}\right] ; \mathrm{C}=\left[\begin{array}{lll}
1 & 0 & 0
\end{array}\right] ; \mathrm{E}=\left[\begin{array}{l}
0 \\
0 \\
1
\end{array}\right]
$$

For the purpose of estimation, the third order ESO is defined by:

$$
\begin{gathered}
\dot{\hat{x}}=\mathrm{A} \hat{x}+\mathrm{B} u+\mathrm{L}(y-\hat{y}) \\
\hat{y}=\mathrm{C} \hat{x}
\end{gathered}
$$

where, $\hat{x}$ and $\hat{y}$ are the estimates of $x$ and $y, \dot{\hat{x}}$ is a time derivative of $\hat{x}$ and $L\left(=\left[\begin{array}{lll}l_{1} & l_{2} & l_{3}\end{array}\right]^{T}\right)$ is the observer gain so that the ESO is stable.

For simplification purposes, all the eigenvalues of the ESO are placed at $-\omega_{0}$ and then the corresponding observer gain $L$ will become:

$$
L=\left[\begin{array}{lll}
l_{1} & l_{2} & l_{3}
\end{array}\right]^{T}=\left[\begin{array}{lll}
3 \omega_{0} & 3 \omega_{0}^{2} & \omega_{0}^{3}
\end{array}\right]^{T}
$$

where, $\omega_{0}$ is the bandwidth of the observer which is tunable. Higher bandwidth makes the observer faster but it makes it more noise prone.

After estimation, the results are the approximations to:

$$
\hat{x}_{1} \rightarrow y ; \hat{x}_{2} \rightarrow \dot{y} ; \hat{x}_{3} \rightarrow f
$$

Then Eq. (1) becomes double-integrator as Eq. (4).

Fig. 3 shows a system plant (with unknown dynamics and disturbances) and the ESO. As the system would ideally be a pure double-integrator, a simple PD (proportional-derivative) controller should be sufficient to control it with input signal $u_{0}$.

$$
u_{0}=k_{p}(r-y)+k_{d}(\dot{r}-\dot{y})
$$

where, $k_{p}$ and $k_{d}$ are the proportional and derivative gains, respectively, of the PD controller, $r$ is constant reference signal and $\dot{r}$ is the time derivative of $r$. 


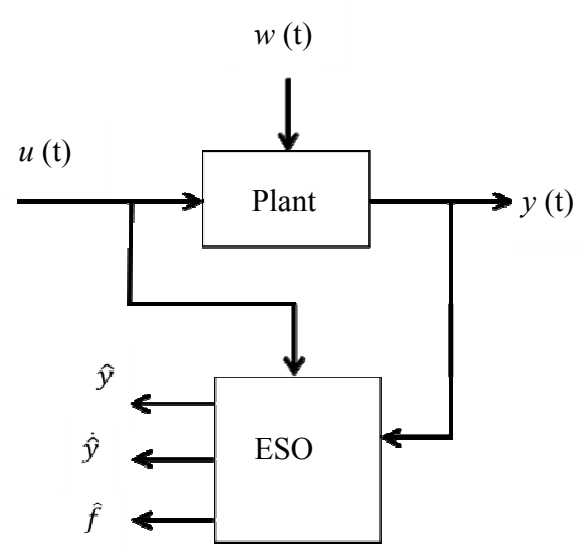

Fig. 3 Plant with ESO.

Choosing the close loop poles at $-\omega_{c}$, then $k_{p}$ and $k_{d}$ are obtained as:

$$
\left.\begin{array}{c}
k_{p}=\omega_{c}^{2} \\
k_{d}=2 \omega_{c}
\end{array}\right]
$$

where, $\omega_{c}$ is a controller bandwidth and is tunable. Tuning of the ADRC is described in detail in Ref. [14].

\section{Simulation}

The test distribution systems presented in Refs. [15-18] are just a single bus system connecting together a source feeder and a sensitive load. Those presented in Refs. [9, 19-22] also consist of a single bus system connected to which is a source feeder, a regular load and a sensitive load. In this paper, the test distribution system is presented with multiple buses and capable of producing multiple PQPs (power quality problems). Thus, this distribution system can be envisioned as a means to study the impact of single or multiple PQPs on several loads of diverse characteristics, to investigate the effectiveness of different algorithms for the control of CUPS devices, and to study the most effective locations of CUPS devices for compensating PQPs.

The MATLAB (matrix laboratory)/Simulink schematic of the test distribution system shown in Fig. 4 , is a three-bus, radial distribution system, where the number of feeders branch out from the main bus (BUS1). For clarity of this presentation, the three buses are depicted as in a normal three-phase system that is not a feature of MATLAB/Simulink, which uses V-I measurement blocks. The feeder source is protected by a circuit breaker (CB1), from faults on any of the radial lines emanating from it.

There are two radial distribution lines tied to BUS1: (1) a line connected between BUS1 and BUS2, at its other end, with circuit breaker (CB2) protecting BUS1 from faults along this line; and (2) the second line between BUS1 and BUS3, with circuit breaker (CB3) protecting BUS1 from faults on this line.

Load (LOAD3) and source (Unbalanced Source) are connected to BUS2 via circuit breakers (CB7 and CB8, respectively). Loads (LOAD1, LOAD2 and LOAD4) are connected to BUS3 via circuit breakers (CB4, CB5, and $\mathrm{CB} 6$, respectively). Each circuit breaker will protect BUS3 from faults in any of the respective loads. In the distribution system, load (LOAD1) is a sensitive load that has to be protected from all PQPs. Load (LOAD2) is a large load which can be made highly inductive or capacitive to generate sag or swell. Load (LOAD3) is an unbalanced, non-sensitive load. Due to this unbalanced load, a voltage imbalance will be observed at BUS2 and will be transferred to BUS1 and BUS3. Load (LOAD4) consists of a three-phase full bridge diode rectifier without a filter, feeding a resistor load, also without a filter, which results in voltage harmonics impressed on BUS3. BUS3 is a PCC (point of common coupling) for loads (LOAD1 and LOAD2). Unbalanced Source is a three-phase unbalanced voltage source. When this source is connected to BUS3, the imbalance in the voltage magnitudes will be observed at BUS2, BUS1, and BUS3. Tables 1-3 give the circuit parameters value for Feeder Source and loads (LOAD1 and LOAD2). More details on the test distribution system are presented in Ref. [23].

This test distribution system will be used to illustrate the application of a DVR for the compensation of voltage sag using both PID and ADRC controller and performances will be compared. A balanced three-phase voltage sag at the sensitive load is produced by turning on load (LOAD2). To illustrate, during the $300 \mathrm{~ms}$ to $700 \mathrm{~ms}$ interval, load (LOAD2) is 


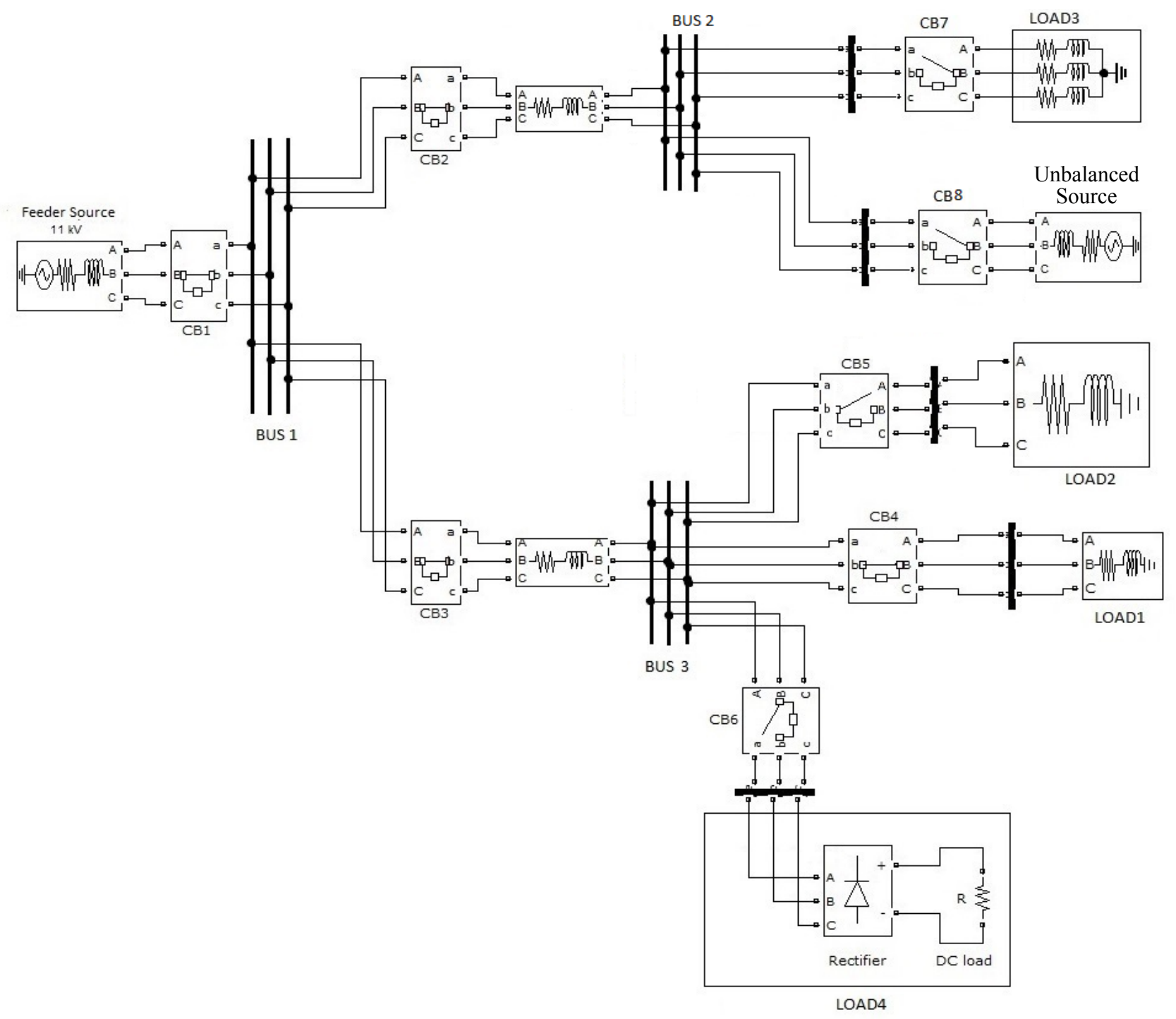

Fig. 4 Test distribution.

Table 1 Feeder source parameters.

\begin{tabular}{ll}
\hline Parameters & Value \\
\hline Phase-phase rms voltage & $11(\mathrm{kV})$ \\
Phase angle of phase A & $0\left(^{\circ}\right)$ \\
Frequency & $60(\mathrm{~Hz})$ \\
Source resistance & $0.1(\Omega)$ \\
Source inductance & $1.86(\mathrm{mH})$ \\
\hline
\end{tabular}

Table 2 Sensitive LOAD1 parameters.

\begin{tabular}{ll}
\hline Parameters & Value \\
\hline Nominal phase-phase rms voltage & $11(\mathrm{kV})$ \\
Nominal frequency & $60(\mathrm{~Hz})$ \\
Active power $(P)$ & $100(\mathrm{~kW})$ \\
Inductive reactive power $(Q L)$ & $100(\mathrm{VAR})$ \\
Capacitive reactive power $(Q c)$ & $0(\mathrm{VAR})$ \\
\hline
\end{tabular}

Table 3 LOAD2 parameters.

\begin{tabular}{lll}
\hline Parameters & $\begin{array}{l}\text { Large } \\
\text { inductive load }\end{array}$ & $\begin{array}{l}\text { Large } \\
\text { capacitive load }\end{array}$ \\
\hline $\begin{array}{l}\text { Nominal phase-phase } \\
\text { rms voltage }\end{array}$ & $11(\mathrm{kV})$ & $11(\mathrm{kV})$ \\
$\begin{array}{l}\text { Nominal frequency } \\
\text { Active power }(P)\end{array}$ & $60(\mathrm{~Hz})$ & $60(\mathrm{~Hz})$ \\
$\begin{array}{l}\text { Inductive reactive } \\
\text { power }(Q L)\end{array}$ & $100(\mathrm{~W})$ & $100(\mathrm{WV})$ \\
$\begin{array}{l}\text { Capacitive reactive } \\
\text { power }(Q c)\end{array}$ & $0(\mathrm{VAR})$ & $0(\mathrm{VAR})$ \\
\hline
\end{tabular}

connected by closing circuit breaker (CB5). The voltage drops by $36.5 \%$ with respect to the per unit reference value. This sag would be seen by the sensitive load if no compensation is provided. 


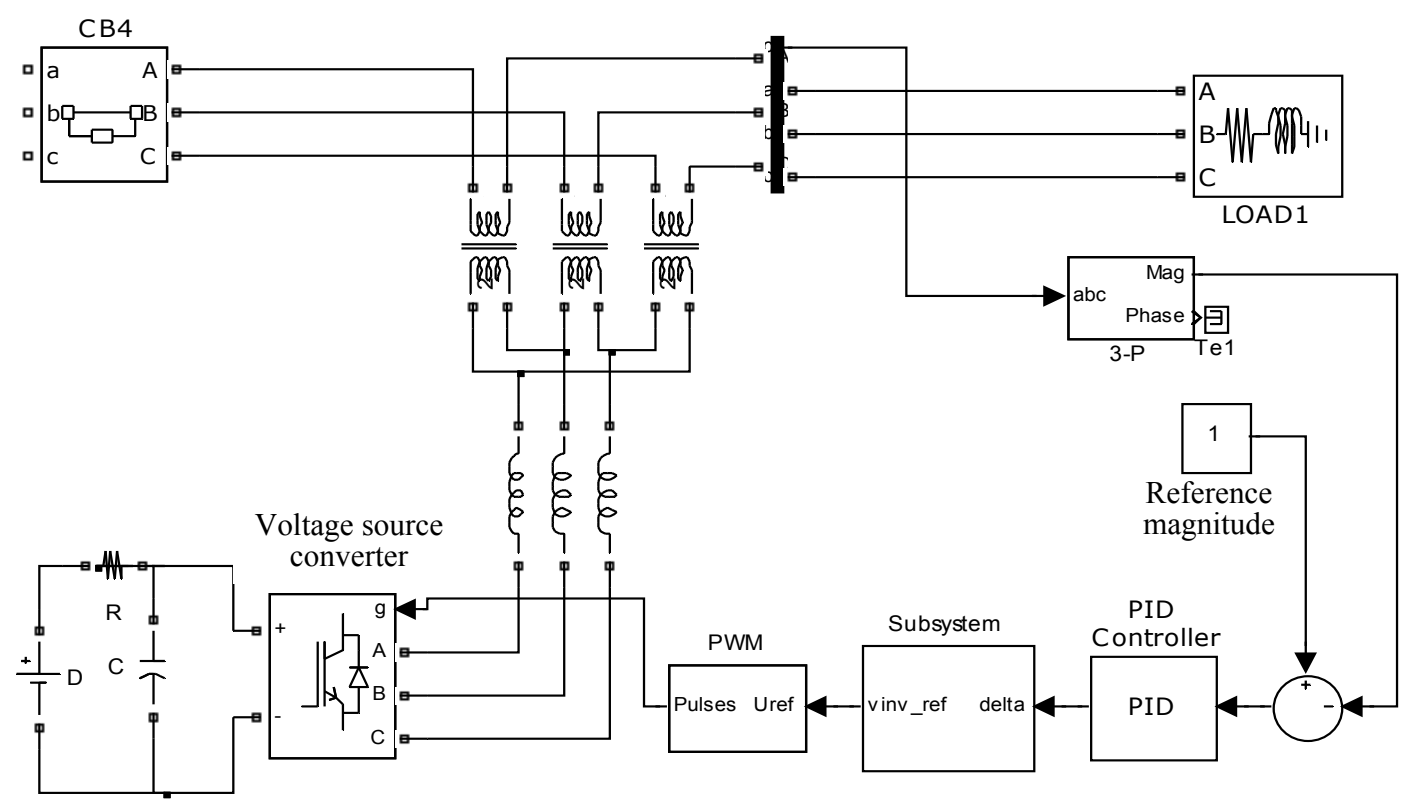

Fig. 5 Partial view of the test system with PID-controlled DVR.

The DVR with a PID-controller is applied between circuit breaker (CB4) and sensitive load (LOAD1) as shown in Fig. 5. Three identical, single-phase, transformers are used to inject the compensating voltages to the distribution line. A six-pulse universal bridge is used as a voltage source converter. The PWM (pulse-width modulation) based control scheme is used to maintain the constant voltage magnitude at the sensitive load terminal. The carrier frequency used for the PWM generator is $5,400 \mathrm{~Hz}$ and generates six pulses required for the voltage source converter. As explained in Ref. [9], this control method does not require measuring reactive power. It only measures rms voltage at the load terminal. The measured voltage is compared with the reference voltage and the error signal is obtained. The PID controller processes the error signal and generates the required delay angle to return the error to zero. The subsystem to generate the reference voltage for PWM generator is shown in Fig. 6. The PWM generator generates the pulses required for the voltage source converter. The voltage level at the load terminal is then brought back to its reference level.

The proportional gain $\left(K_{p}\right)$, integral gain $\left(K_{i}\right)$, and derivative gain $\left(K_{d}\right)$ parameters are chosen using a popular heuristic tuning method called Ziegler-Nichols tunning method. PID controller is choosen where $K_{p}, K_{i}$ and $K_{d}$ are found to be $110,13,000$ and 0 , respectively. Since the derivative gain parameter is equal to zero, the controller is also called PI controller.

An ADRC with a third order ESO is implemented for the DVR. The DVR with an ADRC block is applied between circuit breaker (CB4) and sensitive load (LOAD1), as shown in Fig. 7. Fig. 8 shows the ADRC block used in the simulation, where $x 1 \_h, x 2 \_h$ and $x 3 \_h$ give the estimate of $y, \dot{y}$ and $f$, respectively. The control signal $u_{0}$ is obtained using Eq. (10) where $\dot{r}$ is zero. The controller bandwidth is selected to be 220 , observer bandwidth to be 20 times the controller bandwidth and the parameter $b$ (see Eq. (2)) is set at 1,300.

Fig. 9 shows the performances of the DVR with ADRC and the PID controllers for voltage sag or disturbance compensation. At $t$ (time) $=0.3 \mathrm{sec}$, a disturbance is introduced and at $t=0.7 \mathrm{sec}$, it is cleared. From the plot, at $t=0.3 \mathrm{sec}$, it can be seen that the magnitude of the PR (peak response) with PID controller is $21 \%$ of the nominal value ( $1 \mathrm{pu}$ ), which is higher compared to the one with ADRC which is $9 \%$. Also at $t=0.7 \mathrm{sec}$, the magnitude of PR is $25 \%$ with PID and ADRC is $9 \%$. The $T_{s}$ (settling time) at the 


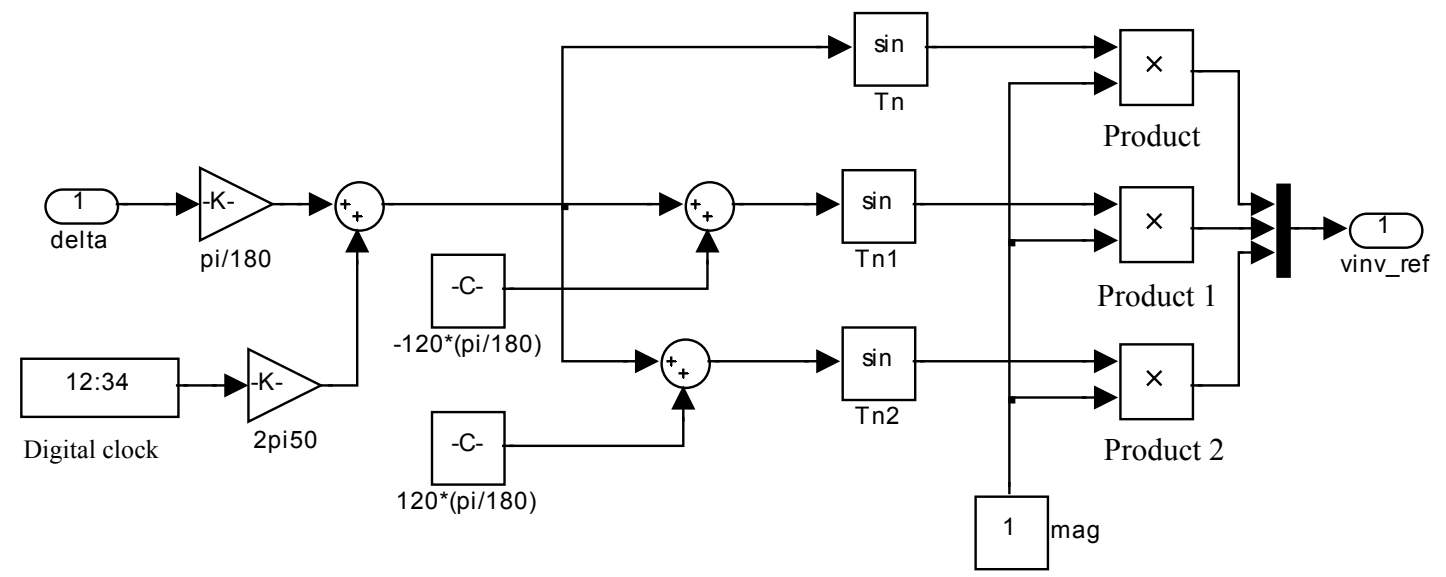

Fig. 6 Subsystem to generate reference voltage.

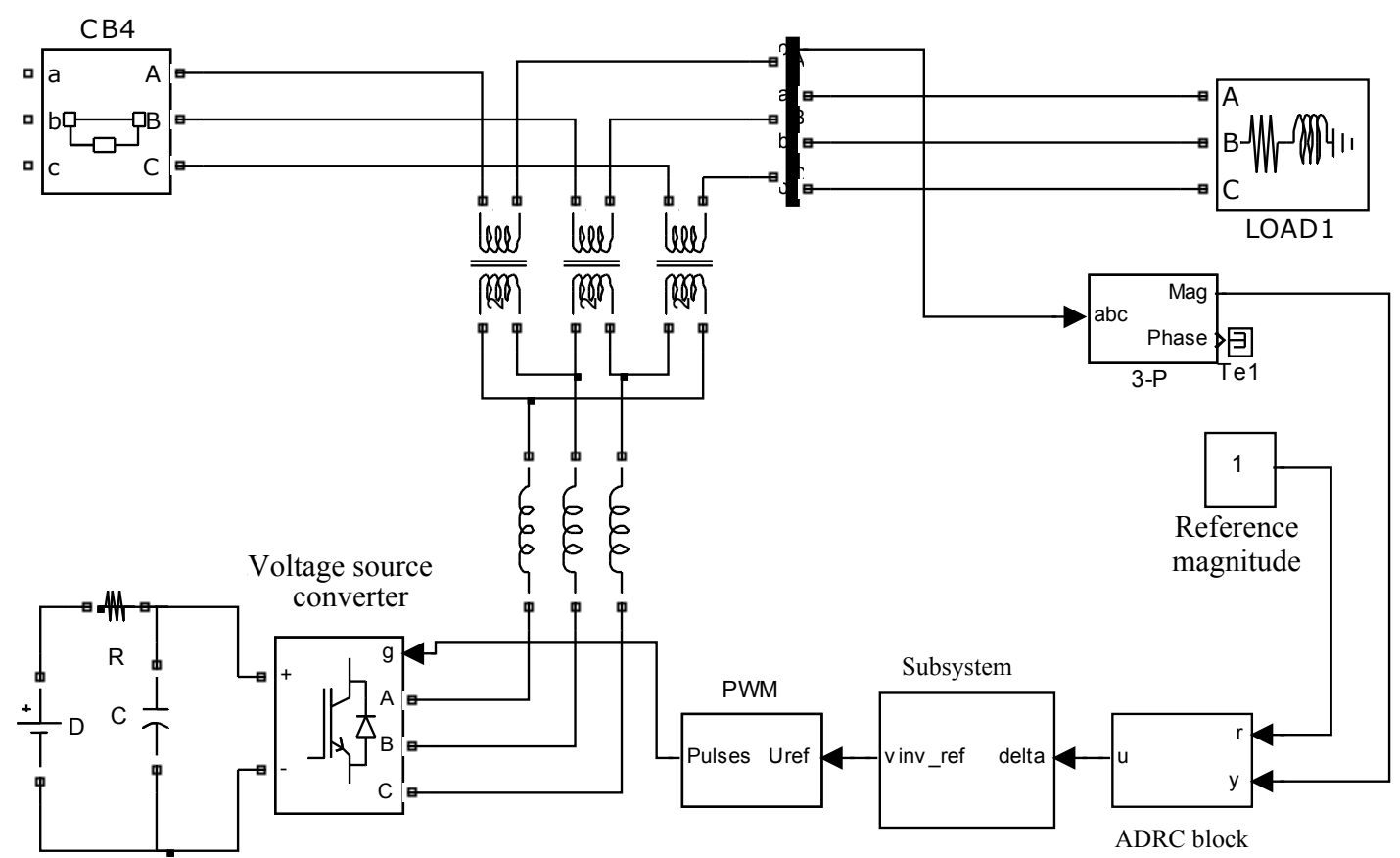

Fig. 7 Partial view of the test system with DVR and ADRC block.

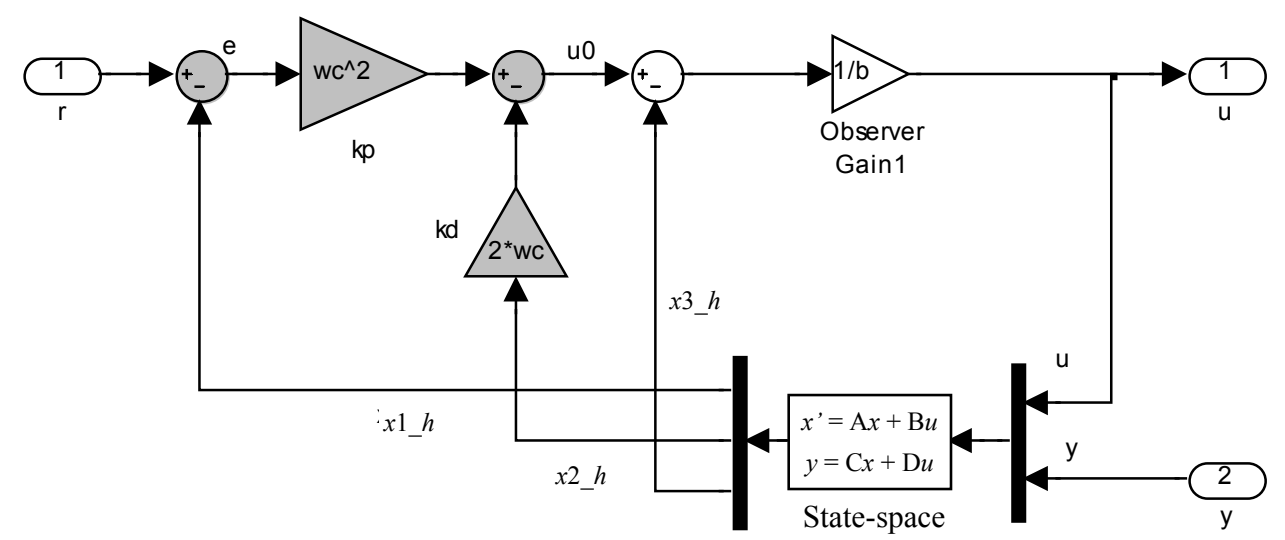

Fig. 8 ADRC block for DVR control. 


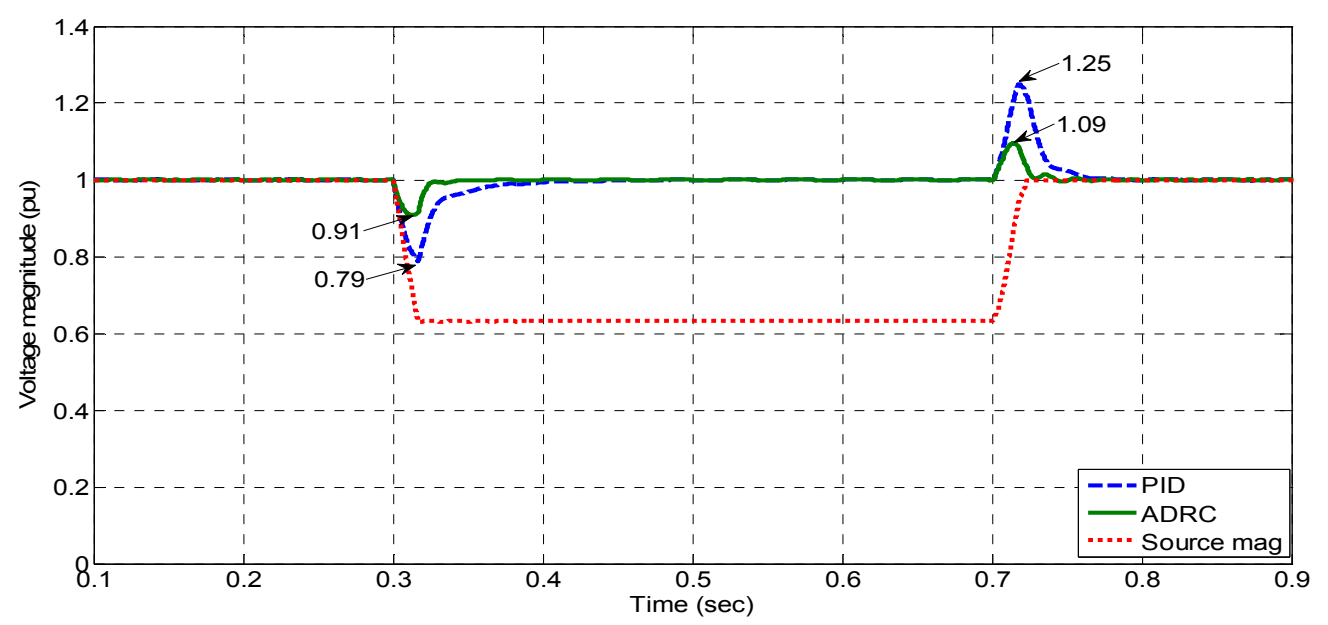

Fig. 9 DVR performance with ADRC and PID controllers.

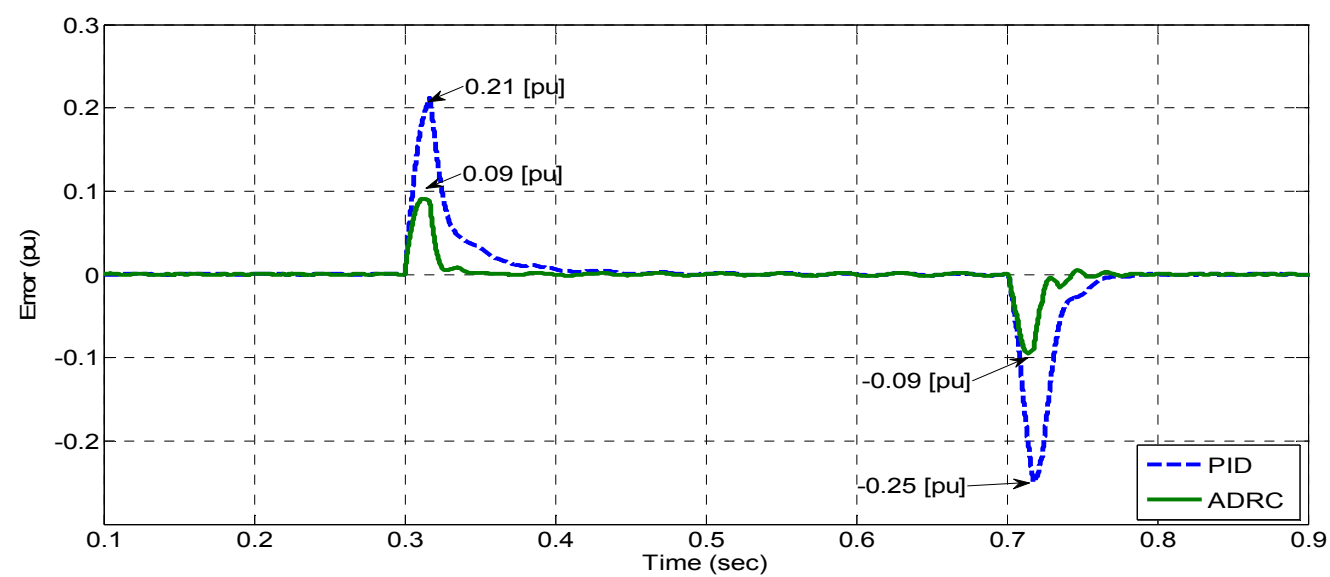

Fig. 10 Error signal for with ADRC and PID controller.

beginning and the end of the disturbance are higher with PID controller than with ADRC controller. Therefore, we can say that the response of the PID controller is slower and requires more control effort than ADRC to bring back the load voltage to the reference level when there is a step change in voltage magnitude. Fig. 10 shows an error voltage magnitude with respect to time using both ADRC and PID controllers. IAE (Integral absolute error) is used to measure the performance of ADRC and PID controller.

It integrates the absolute error over time and is given by:

$$
I A E=\int_{0}^{t}|e(t)| \mathrm{d} t
$$

where, $e(t)$ is an error function. IAE for using ADRC and PID controllers are measured to be 0.0143 and 0.0213. These results are summarized in Table 4 .
Table 4 PID and ADRC performance measure.

\begin{tabular}{clllll}
\hline \multirow{2}{*}{$\begin{array}{l}\text { Control } \\
\text { type }\end{array}$} & \multicolumn{4}{l}{ When disturbance When disturbance } \\
introduced & $\begin{array}{l}\text { removed } \\
\text { rem }\end{array}$ & IAE \\
& $T_{S}$ & $\begin{array}{l}T_{s} \\
(\%)\end{array}$ & $\begin{array}{l}\% O S \\
(\mathrm{~ms})\end{array}$ & $\begin{array}{l}(\%) \\
(\%)\end{array}$ \\
\hline PID & 90 & 21 & 61 & 25 & 0.021 \\
\hline ADRC & 20 & 9 & 39 & 9 & 0.014 \\
\hline
\end{tabular}

\section{Conclusion}

In this paper, the brief introductions to CUPS (custom power systems), and specifically to power quality problems, such as voltage sag, were presented. The structure, the function and the controllers of DVR (dynamic voltage restorer) were discussed. A new control method based on the concept of ADRC (active disturbance rejection control) suitable for DVR is developed to mitigate voltage sags and its performance was compared with highly dominating 
PID controller using MATLAB/Simulink ${ }^{(C}$. Simulation results showed that the DVR controlled by ADRC performed better than with a PI controller for this application.

\section{References}

[1] IEEE. 1995. "IEEE Recommended Practices for Monitoring Electric Power Quality.” IEEE Standard 1159-1995.

[2] Hingorani, N. G. 1995. "Introducing Custom Power." IEEE Spectrum 32 (6): 41-8.

[3] Minorsky, N. 1922. "Directional Stability of Automatically Steered Bodies." Journal of the American Society for Naval Engineers 34: 280-309.

[4] Samad, T., and Annaswamy, A. M. 2011. "The Impact of Control Technology." IEEE Control Systems Society. Accessed February 13, 2013. http:// www.ieeecss.org.

[5] Han, J. 2009. "From PID to Active Disturbance Rejection Control." IEEE Transaction on Industrial Electronics 56 (3): 900-6.

[6] Nielsen, J. G., and Blaabjerg, F. 2005. "A Detailed Comparison of System Topologies for Dynamic Voltage Restorers." IEEE Transactions on Industry Applications 41 (5): 1272-80.

[7] Ghosh, A., and Ledwich, G. 2002. "Compensation of Distribution System Voltage Using DVR.” IEEE Transaction on Power Delivery 17 (4): 1030-6.

[8] Jin, W., Aiqin, X., and Yueyue, S. 2008. "A Survey on Control Strategies of Dynamic Voltage Restorer." In Proceedings of 2008 International Conference on Harmonics and Quality of Power, 1-5.

[9] Lara, O. A. and Acha, E. 2002. "Modeling and Analysis of Custom Power Systems by PSCAD/EMTDC." IEEE Transaction on Power Delivery 17 (1): 266-72.

[10] Petkova, M., Antchev, M., and Gourgoulitsov, V. 2011. "Investigation of Single-Phase Inverter and Single-Phase Series Active Power Filter with Sliding Mode Control." Sliding Mode Control 25-44. Accessed August 23, 2014. http://www.intechopen.com.

[11] Antchev, M., Petkova, M., Antchev, H., Gourgoulitsov, V., and Valtchev, S. 2012. "Study of Single-Phase Series Active Power Filter with Hysteresis Control." Journal of Energy and Power Engineering 10: 1634-41.

[12] Antchev, M. H., Petkova, M., Gourgoulitsov, V., and Antchev, H. 2012. "Investigation of 'Unified Voltage Conditioner'-UVC." Journal of Power Electronics 12 (2): 357-67.

[13] Gao, Z. 2006. "Active Disturbance Rejection Control: A Paradigm Shift in Feedback Control System Design.” In
Proceedings of 2006 American Control Conference, 2399-405

[14] Gao, Z. 2003. "Scaling and Bandwidth-Parametrization Based Controller Tuning." In Proceedings of 2003 American Control Conference, 4989-96.

[15] Ghosh, H., Saha, P. K., and Panda, G. K. 2012. "Performance Comparison between DVR and DSTATCOM Used for Load Voltage in Distribution Side." In Proceedings of 2012 International Conference on Advances in Power Conversion and Energy Technologies, 1-6.

[16] Haque, M. H. 2001. "Compensation of Distribution System Voltage Sag by DVR and D-STATCOM." Presented at IEEE 2001 Porto Power Tech Conference, Porto, Portugal.

[17] Mohammed, B. S., Rao, K. S. R., and Perumal, N. 2011. "Cascade Multi-level Converter Based DVR and D-STATCOM for Voltage Sag and Swell Reduction." In Proceedings of 2011 ISCI IEEE Symposium on Computers \& Informatics, 390-5.

[18] Hatami, H., Shahnia, F., Pashaei, A., and Hosseini, S. H. 2007. "Investigation on D-STATCOM and DVR Operation for Voltage Control in Distribution Networks with a New Control Strategy." In Proceedings of 2007 IEEE Lausanne Power Tech Conference, Lausanne, 2207-12.

[19] Madhusudanl, R., and Rao, G. R. 2012. "Modeling and Simulation of a Dynamic Voltage Restorer (DVR) for Power Quality Problems Voltage Sags and Swells." In Proceedings of 2012 International Conference on Advances in Engineering, Science and Management, 442-7.

[20] Kumarand, S. V. R., and Nagaraju, S. S. 2007. "Simulation of D-STATCOM and DVR in Power Systems." ARPN Journal of Engineering and Applied Sciences 2 (3): 7-13.

[21] Ndubuka, N. M. 2011. "Power Quality Enhancement of Nigerian Power Distribution Systems by Use of Distribution Static Compensator (D-STATCOM)." International Journal of Electrical and Power Engineering 5 (1): 8-12.

[22] Deokar, S. A., and Waghmare, L. M. 2012. "DVR Control Strategy for Dynamic Power Quality Disturbance Mitigation." International Journal of Scientific and Research Publications 2 (11): 1-9.

[23] Tuladhar, L., and Villaseca, F. E. 2014. “A Benchmark Distribution System for the Study of Power Quality Problems and their Compensation." In Proceedings of the 12th International Energy Conversion Engineering Conference, 1-6. 